Plínio de Oliveira Corrêa, professor de direito processual penal nas Faculdades de Direito da Universidade Federal do Rio Grande do Sul UFRGS - e da Pontifícia Universidade Católica do Rio Grande do Sul - PUCRGS.
Plínio de Oliveira Corrêa

\title{
Justa causa na reforma processual penal brasileira
}

Há mais de vinte anos que a minha geração vive a expectativa da reforma do atual Código de processo penal - CPP. Nestas duas décadas, quase todas as atenções dos estudiosos da ciência do processo penal brasileiro têm se voltado para os temas propostos em dois conhecidos anteprojetos - o primeiro, de autoria do professor Hélio Bastos Tornaghi; e o segundo, da lavra do professor José Frederico Marques. Na verdade, essa expectativa tem acarretado vantagens e desvantagens à evolução do desenvolvimento científico-cultural nesse ramo do conhecimento jurídico.

Assim, se de um lado foram aprofundados os estudos sobre velhos e novos institutos, de outra parte é preciso reconhecer que a injustificável demora com que se processa a almejada reforma tem trazido prejuízos incalculáveis à justiça distributiva deste país, cansada não apenas de esperar „por normas processuais adequadas à realização do moderno direito penal, mas, sobretudo, exausta de suportar o jugo de um Código improvisado, assistemático e retrógrado, como é o de 1941.

Dentre os pontos negativos proporcionados por essa demora, cabe sublinhar as inúmeras obras ou produções científicas que deixaram de ser publicadas neste quatro lustros pelo simples receio de já nascerem envelhecidas com a eventual e surpreendente edição do prometido Diploma.

Tal situação teve início quando a tarefa de elaborar um anteprojeto de Código foi confiada a um eminente jurista pátrio - o professor Hélio Bastos Tornaghi - que, em prazo relativamente curto, desincumbiu-se do honroso encargo, encaminhan- do o resultado do seu trabalho ao senhor ministro da Justiça do governo João Goulart.

Após o movimento político de 1964, e por razões que não vêm ao caso agora examinar, o Anteprojeto Tornaghi, no entanto, foi desativado, culminando o governo Médici por confiar aquela tarefa a outro ilustre jurisconsulto brasileiro - o professor José Frederico Marques, que em 1970 concluiu o seu trabalho.

Este anteprojeto foi analisado por uma comissão revisora, instituida pelo Ministério da Justiça e integrada por um civilista e por dois penalistas, respectivamente, os professores José Carlos Moreira Alves, Benjamin Moraes Filho e José Salgado Martins. Somente com o lamentável falecimento de um de seus membros - o professor Salgado Martins é que veio, finalmente, participar da comissão um renomado processualista penal, o professor Hélio Bastos Tornaghi, autor do primeiro anteprojeto.

Concluída a revisão, e através da mensagem presidencial n: 159/75, o Poder Executivo encaminhou o Projeto de Código ao Congresso Nacional, onde tramitou regularmente sob o $n$. 633/75, inaugurando-se, então, na comissão especial da Câmara dos Deputados um grande ciclo de debates em torno do seu conteúdo (junho/75 a novembro/77). Deste debate nacional, do qual tomaram parte inúmeros professores, advogados, magistrados e membros do ministério público, resultou a apresentação de 784 emendas, muitas delas acolhidas pela comissão especial e posteriormente pelo plenário da Câmara dos Deputados. 
Quando o projeto já tramitava normalmente no Senado Federal sob o n: 05/78, o mundo jurídico brasileiro foi surpreendido com a sua retirada do Congresso Nacional pelo Poder Executivo, sob a alegação da necessidade de 'reexame' do seu conteúdo, conforme diz a mensagem presidencial de 30 de agosto de 1978.

Para proceder ao 'reexame' do citado projeto - que por isso mesmo retrocedeu à posição de anteprojeto - nomeou-se a nova comissão ministerial, integrada pelos professores Rogério Lauria Tucci, Francisco de Assis Toledo e Hélio Fonseca. O trabalho desempenhado por essa comissão contou com a colaboração da nossa elite cultural, recebendo sugestões, críticas e emendas ao anteprojeto; formuladas individualmente e através de vários congressos, seminários e encontros levados a efeito em todo o país.

Como remate desses estudos, submeteu-se o texto a duas revisões complementares: uma, lingüística, pelo professor Aires da Mata Machado; e outra, técnico-jurídica, pelo professor José Frederico Marques, autor do anteprojeto original, que "acoIheu as principais inovações introduzidas e apresentou quase uma centena de novas modificações, as quais foram incorporadas no anteprojeto".

Da soma de todos esses esforços, resultou o texto do atual anteprojeto, que agora será novamente remetido ao Congresso Nacional para tramitar, primeiramente, na Câmara dos Deputados e, depois, no Senado da República.

Conseqüentemente, reabre-se um novo e grande debate em torno da matéria, ensejando novas críticas, possibilitando novas emendas, motivando novas sugestões e instaurando novos congressos e seminários por parte daquelas instituições que são responsáveis pelo aperfeiçoamento da ordem jurídica brasileira.

Eis o porquê deste Ciclo de Estudos, promovido em boa hora pelo Instituto dos Advogados Brasileiros, no qual há de se tratar dos diferentes e relevantes temas propostos pela atual reforma penal, que auguro e se concretize finalmente e rapidamente.

\section{1 - Diferentes significados da justa causa}

"A justa causa na reforma processual penal brasileira" é o tema que me coube tratar neste Encontro, a título de modesta contribuição intelectual a ser submetida à apreciação crítica de todos os participantes deste ciclo de estudos.

No processo penal brasileiro, a expressão 'justa causa' assume diferentes significados, que podem ser compreendidos em seis posições ou correntes de pensamento, a saber:

\section{1 - a primeira posição vinculada a justa cau-} sa ao conceito de prisão;

2 - a segunda utiliza-a para fundamentar a concessão de habeas corpus quando o fato imputado não constituir infração penal;

3 - a terceira fixa a falta de justa causa como figura equivalente às hipóteses do artigo 43 do Código de processo penal - CPP;

4 - a quarta a situa como elemento idenficador dos casos de coação ou constrangimento ilegal;

5 - a quinta a elimina do sistema processual penal brasileiro;

6 - e finalmente, a sexta posição coloca a justa causa como uma das condições da ação penal.

\section{II - Crítica às diferentes posições}

Em seguida, torna-se imprescindível fazer, ainda que rapidamente, uma análise crítica desses posicionamentos, para melhor se atingir ou a natureza jurídica do instituto, ou, pelo menos, para se saber onde a reforma situa a justa causa dentro do quadro proposto

Assim, quanto à primeira posição - isto é, a que liga a justa causa ao conceito de prisão - cabe destacar que ela remonta ao Código de processo $\mathrm{Cr}^{-}$minal de 1832, ao consagrar esse preceito no artigo 353: ela".

"A prisão julgar-se-á ilegal:

1. - quando não houver justa causa para

No mesmo sentido, o decreto $n: 3.084$, de 5 de novembro de 1898, que consolidou as Leis da Justiça Federal, prescrevia no seu artigo 360 que a prisão seria ilegal quando não houvesse justa causa para ela.

Fiel a essa orientação, e até refletindo a legis lação ordinária então existente, o Supremo Tribunal Federal, no seu regimento interno de 24 de maio de 1909, estabelecia no artigo 112 que: ilegal:

"A prisão, ou constrangimento, se julgará

1) quando não tiver justa causa".

Os códigos de processo penal dos estados que representam o fruto da consagração do princíde 1891, e que perduraram até 1941 - , por sua vez, 
e com raras exceções, continham disposições idênticas, considerando a justa causa como motivo determinante da legalidade da prisão, se presente, ou da ilegalidade, quando ausente.

No entanto, esse entendimento merece ser criticado, uma vez que não se concebe hoje, como não se concebia ontem, condicionar-se a idéia de justa causa ao conceito de legalidade ou de ilegalidade da prisão. E a razão é simples: a prisão pode ser legal, como ocorre com as prisões administrativa, disciplinar e para averiguação, e inexistir legitimidade para qualquer uma delas, como já tive oportunidade de demonstrar em estudo intitulado Autoridade competente para ordenar a prisão no direito brasileiro, Editora da UFRGS, 1981.

Por conseguinte, não mais se pode falar em legalidade ou ilegalidade, mas em legitimidade ou ilegitimidade da prisão.

No que diz respeito à segunda posição, aquela que utiliza a justa causa para fundamentar a concessão de habeas corpus quando o fato imputado não constitui crime, encontrou embasamento legal, inicialmente, em três códigos estaduais: o do Rio Grando do Sul, o do então Distrito Federal e o de Santa Catarina. Estes três diplomas, apesar de ainda manterem a linha tradicional antes referida, trouxeram algumas inovações que caracterizam essa corrente de pensamento.

O primeiro, o do Rio Grande do Sul, considerava nos artigos 254 e 255 da lei estudual n. 24, de 15 de agosto de 1898 (com as modificações introduzidas pela lei n. 141, de 23 de julho de 1912) a imputação de 'fato não criminoso' como constrangimento ilegal ou abusivo para se conceder habeas corpus por falta de justa causa.

O segundo, o do Distrito Federal, estatuía no decreto n: 8.259, de 29 de setembro de 1910, assinado pelo presidente Nilo Peçanha, esse princípio no artigo 382:

"A prisão ou constrangimento jułgar-se-á ilegal em qualquer dos seguintes casos:

1. - Quando não houver justa causa ou o fato não constituir crime".

E o terceiro, o de Santa Catarina, promulgado pela lei estadual n: 1.640, de 3 de novembro de 1928, depois de valorizar a justa causa no art. 2.564, determinava no artigo 2.565:

"Ainda depois da pronúncia ou da condenacão, o habeas corpus pode ser concedido nos seguintes casos: [ . . . ]

crime"
Esse posicionamento encontrou ressonância não só na jurisprudência dos nossos tribunais, mas também na palavra de ilustrados mestres do direito, como Florêncio Carlos de Abreu e Silva, que afirmava não existir justa causa "quando o fato de que o paciente é acusado não constituir crime ou contravenção penal" (Comentários ao Código de processo penal, vol.V, p.565, Forense, 1945).

A crítica que pesa sobre essa posição pode restringir-se no seguinte: se o fato narrado na peça inicial não constituir crime, o juiz deve, de imediato, aplicar o preceito contido no artigo 43 , inciso I, do Código de processo penal - CPP, que diz:

"A denúncia ou queixa será rejeitada quando:

I - o fato narrado evidentemente não constituir crime".

Logo, se existe regra expressa regulando a matéria, não deve haver lugar para metáfora jurídica ou qualquer outro simbolismo ainda insuficientemente definido.

Ademais, não existe conveniência alguma em apelidar ou cognominar de justa causa a temas com denominações próprias e já devidamente assentados na literatura jurídica.

A terceira posição é mais recente e surgiu com o advento do atual Código de processo penal CPP, de 1941. Este Código resultou do retorno do princípio da unidade processual, que passou a vigorar no nosso sistema constitucional a partir da Constituição de 1934, perdurando até hoje, o qual aboliu conseqüentemente o regime dos códigos estaduais e instituiu um único código nacional, promulgado pelo decreto-lei n? 3.689/941.

A citada posição define a falta de justa causa como elemento equivalente às hipóteses previstas no artigo 43 desse Código nacional, assim definidas:

"A denúncia ou queixa será rejeitada quando: I - o fato narrado evidentemente não constituir crime; II - já estiver extinta a punibilidade, pela prescrição ou outra causa; III - for manifesta a ilegalidade da parte ou faltar condição exigida pela lei para o exercício da ação penal".

Regra semelhante consta do artigo 78 do Código de processo penal militar (decreto-lei n: 1.002, de 21 de outubro de 1969)

Como se verifica pela leitura do mencionado artigo 43 e seu incisos, este contém casos de diferentes naturezas, tais como: elementos formais da peça acusatória, extinção de punibilidade e condições genéricas da ação penal.

Tal artigo compreende, assistematicamente, uma miscelânea de diversoso institutos. Dessa for- 
ma, é inconcebivel pretender-se que a expressão jușta causa compreenda, traduza ou reflita por ela mesma todos esses temas e situações heterogêneas.

Entre os autores modernos que, data maxima venia, incorrem nessa injustificável equiparação estão Darcy Arruda Miranda (Comentários à lei de imprensa, vol.II, p. 744, Editora Revista dos Tribunais, 1969), Freitas Nobre (A lei de imprensa, p. 206, Saraiva, 1968) e José Raimundo Gomes da Cruz (artigo publicado na Revista dos Tribunais, vol. 423, p. 303 e segs.).

A quarta posição situa a falta de justa causa como elemento identificador dos demais casos de coação ou de constrangimento ilegal enumerados no artigo 648 do Código de processo penal - CPP, que dispõe:

"Art. 648 - A coação considerar-se-á ilegal: I - quando não houver justa causa; || - quando alguém estiver preso por mais tempo do que determina a lei; III - quando quem ordenar a coação não tiver competência para fazê-lo; IV - quando houver cessado o motivo que autorizou a coação; V quando não for alguém admitido a prestar fiança, nos casos em que a tei a autoriza; VI - quando o processo for manifestamente nulo; VII - quando extinta a punibilidade".

Idêntica regra prevê o artigo 467 do Código de processo penal militar.

Esta posição, em parte, é defendida pelo professor José Frederico Marques, para quem, nos casos referidos, a justa causa funcionaria "como norma genérica de encerramento" (Elementos de direito processual penal, vol. IV, Forense, 1965, p. 398).

Com efeito, ao analisarmos as hipóteses do artigo 648 do Código de processo penal - CPP, constatamos a presença de questões relativas à competência, a pressupostos processuais, à prestação de fiança, a nulidades processuais, a excesso de prazo na prisão, entre outras. Por conseguinte, aqui também é inconcebivel a utilização da justa causa como expressão universal para identificar os mais variados institutos e as mais diversas situações jurídicas. A identificação pretendida nessa posição, assim como a equivalência sugerida na anterior, não passam de meras opiniões destituídas, data venia, de qualquer valor científico.

A quinta posição é a que elimina a expressão justa causa do nosso sistema processual penal, tendo como justificativa a heterogeneidade de tratamento e a dificuldade de conciliar a divergência de significação. Este é o posicionamento do professor Tornaghi, ou, pelo menos, o que se retira do seu anteprojeto, o qual simplesmente ignora a justa causa, não a tendo mencionado nem mesmo nos ca- sos de coação ou constrangimento ilegal, tradicionalmente consagrada para fins de conhecimento e concessão de habeas corpus.

Acompanha esse entendimento José Raimundo Gomes da Cruz, em artigo publicado na Revista Justitia (vol. 58, p. 70), onde sugere expressamente a sua supressão dos textos nos quais figura na nossa legislação processual penal

A crítica que se pode fazer a essa posição é que ela peca por omissão, esquecendo de bem conceituar um instituto que há mais de 150 anos figura na legislação brasileira. Esta omissão por parte dos nossos doutrinadores é, na verdade, injustificável.

\section{III - A justa causa no anteprojeto}

A sexta e última posição, como já se viu, é a que situa a justa causa como uma das condições da ação penal. Esta corrente doutrinária foi acolhida pelo nosso direito positivo com a edição da lei n: 5.250 , de 9 de fevereiro de 1967, que regula a liberdade de manifestação do pensamento. 0 § 10 do artigo 44 dessa lei não deixa a menor dúvida quanto à definitiva incorporação do instituto da justa causa como uma condição da ação penal. Diz o aludido preceito: "A denúncia ou queixa será rejeitada quando não houver justa causa para a ação penal".

Esse posicionamento foi acolhido, também especialmente, pelo anteprojeto do professor José Frederico Marques, não só após o reexame oficial recentemente realizado pelo Ministério da Justiça, mas também desde a publicação do texto original no Diário Oficial da União, em 1970; e, ainda, naquele que resultou da aprovação pela Câmara dos Deputados, em 1977.

Nesse particular, desejo registrar, desde logo, que esta é a posição doutrinária que tenho adotado ao longo destes 17 anos de magistério jurídico, e não seria ademais confessar que para ela fui despertado pelo gênio de Ney Messias, mestre e amigo, de quem não só tive a honra de ter sido discípulo e assistente, como também, muito cedo ainda, herdei a pesada responsabilidade que o destino me impôs de sucedê-lo na regência da cátedra de processo penal na Faculdade de Direito da Universidade Federal do Rio Grande do Sul.

Definida, assim, a posição do anteprojeto em relação à justa causa - que a considera uma das condicões da ação penal - , cabe agora, sem maiores delongas e antes de finalizar esta exposição, que se defina o instituto, afastado-se daqui para diante qualquer equívoco na sua utilização nos meios forenses.

Com isso, e tendo como palco o Instituto dos 
Advogados Brasileiros, estaremos resgatando uma dívida sesquicentenária para com a expressão justa causa, que é 'coisa nossa', pois inexiste similar na literatura estrangeira - a de situá-la adequadamente como condição da ação penal e, principalmente, de estabelecer as bases científicas para a sua conceituação.

\section{IV - Conceito de justa causa}

Peço vênia, portanto, para registrar aqui parte de um estudo que há algum tempo elaborei a propósito do conceito de justa causa no processo penal:

"O direito de petição é uma garantia tradicionalmente assegurada no direito constitucional brasileiro, e, particularmente, no 'Capítulo dos direitos e garantias individuais' da atual Constituição da República?' Do gênero - direito constitucional de petição - decorre a espécie ${ }^{2}$, isto é, o direito à provocação jurisdicional ${ }^{3}$, donde resulta, especificamente, o direito de ação penal ${ }^{4}$.

Representa o direito de petição a forma mais ampla e democrática dos cidadãos, em geral, reivindicarem providências do Estado-Administração; ao passo que o direito de ação penal é o modo pelo qual determinadas pessoas (apenas as legítimas e dotadas de capacidade para serem partes) podem bater à porta do Estado-Jurisdição em busca do concreto enquadramento de uma hipótese delitiva a um tipo penal.

Como se vê, derivam dai duas situaç̃̃es jurídicas distintas: enquanto no direito de petição o postulante pede um benefício para si ou para outrem, no direito de ação penal o seu autor requer um malefício para outrem, ou seja, uma condenação para 0 acusado ${ }^{5}$. Configura-se, nesta última, um conflito de interesses entre o jus persequendi do acusador e o status libertatis do acusado, que só pode ser desatado em definitivo pela prestação jurisdicional, através do devido processo legal

Se, de um lado, o direito de petição é amplo e lilmitado, de outro, o direito de ação penal é, e deve ser, restrito e condicionado. Por isso, e a fim de afastar abuso de direito e/ou de prevenir lesão à liberdade individual, só se admite o exercício do direito de ação penal se se fizerem presentes requisitos gerais $^{6}$, especiais ${ }^{7}$ e formais ${ }^{8}$, traduzidos nas chamadas condições da ação penal.

Assim, entre as condições gerais destaca-se a justa causa, não só como condição primeira da ação penal, mas, sobretudo, como base fundamental do legítimo exercício desse direito. É preciso conhecer, porém, que a idéia decorrente dessa expressão justa causa - tem assumido entre nós significado múltiplo, como se verifica nos diversos ramos da ciência do direito, ou sëja, no direito civil e no processo civil; no direito do trabalho e no processo trabalhista; no direito penal e no processo penal.

Em que pese essa constatação, somada a divergências doutrinárias ${ }^{9}$, já é tempo de enfrentar e de superar o problema, tentando precisar exatamente o conceito de justa causa no processo penal, a fim de se distribuir justiça como Valor $^{10} \mathrm{e}$ de se prevenir injustiças como negação do direito.

A elaboração desse conceito, todavia, só será viável se estiver alicerçada em dois pilares: a) na prova induvidosa da ocorrência de um fato hipoteticamente delituoso; e b) na prova ou indícios, da autoria desse fato. Na verdade, é nisso que consiste o fundamento razoável ${ }^{11}$ para se acionar o jus actionis sem arranhar o princípio da presunção de inocência ${ }^{12}$ no seu aspecto formal.

E este fundamento razoável, sem o qual inexiste justa causa para a instauração do processo penal, advém da fase preparatória da ação penal, a qual é integrada pelo inquérito policial ou por elementos de informação que, necessariamente, devem acompanhar a denúncia ou a queixa, a fim de servir de base à acusação ${ }^{13}$. Por isso, o exame para se constatar a presença ou a ausência de justa causa na ação penal há de recair nas provas que constituem esta fase pré-processual ${ }^{14}$.

Assim sendo, é plenamente justificável, em processo de habeas corpus, o reexame 'dos elementos que serviram de base à acusação para apurar-se se existe justa causa para a ação penal' ${ }^{\prime 15}$. Como se vê, justa causa é essencialmente uma questão de prova, restrita, aliás, à existência de fato delituoso e aos indícios de sua autoria, cujos marcos irão delimitar o objeto do habeas corpus, impetrado com fundamento no art. 648, inciso I, do Código de processo penal - CCP16.

Eis porque não se pode recomendar o entendimento jurisprudencial de que 'estando descrito, na denúncia, fato criminoso, em tese, há justa causa para ação penal' ${ }^{17}$ pois tal narrativa, mesmo configurando uma infração penal, pode resultar 'de pura criação mental da acusação'18. Ademais, a noção de justa causa não se retira dos elementos formais da peça inicial acusatória, mas da base que a instituiu, isto é, da prova que espelha a idoneidade da imputação

Sem isso, estaremos diante de denúncias vazias, por serem destituídas de qualquer fundamento jurídico ${ }^{11}$, as quais representam não só uma ameaça ilegítima à liberdade dos cidadãos, mas também um desrespeito aos seus direitos fundamentais, especialmente o da presunção de inocência ${ }^{12}$, que, no estado de direito, somente pode ser quebrado nu- 
ma destas duas únicas circunstâncias: se existir justa causa para o processo (aspecto formal) ou se houver trânsito em julgado da sentença condenatória (aspecto material). No primeiro caso, admite-se que alguém suporte os inconvenientes de um processo jurisdicional; no segundo, a presunção não é mais de inocência e sim de culpabilidade ${ }^{19}$.

Pelas mesmas razões, não se pode conceder validade jurídica ${ }^{20}$ a preceito legal que, direta ou indiretamente, dispensa a prova da existência de fato delituoso e, pelo menos, de indícios de sua autoria, como acontece, entre outros diplomas ${ }^{21}$, com o conteúdo do artigo 513 do Código de processo penal, o qual cuida fundamentalmente da liberdade do homem; tal situação, porém, não se faz presente no processo civil, que trata de coisas em geral. Neste último ramo, embora não tenha sido batizada de justa causa, a existência desta prova já tem tradição jurídica, uma vez que com esse sentido figura na respectiva legislação há mais de três décadas 22 .

As normas do direito comparado ${ }^{23}$, conjugadas com os elementos já referidos, também fornecem preciosos subsídios para a elaboração conceitual que submeto à apreciação crítica do mundo jurídico: justa causa, comio condição primeira para o exercício da ação penal, consiste na prova da existência de uma hipótese delitiva e, pelo menos, em indícios de sua autoria." ("Falta de justa causa no procedimento penal por crimes de responsabilidade dos funcionários públicos" - Comunicação apresentada no VII. Encontro de COSJUB, realizado em Vitória(ES), de 8 a 13 de agosto de 1982).

\section{Notas} $\S 30$

1. Constituicão da República Federativa do Brasil, art. 153

2. LACERDA, Galeno. Ensaio de uma teoria eclética da ação Revista da Faculdade de Direito da UFRGS. (1): 90, 1958

3. CORRÊA, Plínio de Oliveira. A provocação jurisdicional S.I., Ediçס̃es UFRGS, 1978.

4. Código penal, arts. 102 a 107. Código de processo penal. arts. 24 a 62.

5. A condenação do acusado traduz-se na aplicação das se guintes penalidades: a) pena privativa da liberdade (de reclusão ou de detenção); b) pena de multa; c) penas acessórias (perda de função pública, eletiva ou de nomeação; interdições de direitos; publicação da sentença); d) medidas de segurança (pressupondo a periculosidade do agente)

6. Condições gerais: a) justa causa; b) legitimidade e capacidade para ser parte; c) possibilidade jurídica da imputação (e do conseqüente pedido e da sanção); d) interesse relevante.

7. Condições especiais: a) representação (do ofendido, governamental ou diplomática, conforme o caso); b) licença parlamentar; c) impeachment do presidente da República e do(s) governador(es) do(s) estado(s) federado(s); d) declaração de falência nos crimes falimentares; e) notificação da empresa permissio- nária ou concessionárias nos crimes de imprensa, praticados atra vés de radiodifusão; f) entrada do agente no território nacional.

8. Condiç̃es formais: a) introdução (juízo a que é dirigida, nomes das partes e sua qualificacão, bem como a espécie ou natureza da ação); b) narração (exposição do fato delituoso com todas as suas circunstâncias); c) tipificação ou classificação legal; d) petitório (pedido de recebimento da iniciäl, de citação do acusado e de sua condenação, além de outras especificações, como pedido de prisão preventiva, diligências, etc.); e) complementos (rol de testemunhas e os termos finais de praxe, como pedido de deferimento, data, local e assinatura do titular do direito de ação).

9. Armando Pereira da Câmara apud CORRĖA, Plínio de Oliveira. A provocação jurisdicional. Edições UFRGS, 1978. p.13

10. FOWLER, Fernando (Revista do Ministério Público do Paraná, 7: 81 ess.; BREDA. Antônio Acir (Revista de Direito Penal. 11/12: 52 e ss.); TOURINHO, Filho (Processo penal, s.l., v. 4. p.418, 1979); CRUZZ, José Raimundo Gomes da (Revista Forense. 226: 404 e ss.); ROSA, Inocêncio Borges da (Processo penal brasileiro. v. 4, p. 191): TORNAGHI. Hélio Bastos (Anteprojeto de Código de processo penal. art.23, letras a e $b$ ); MARQUES, José Frederico (Elementos de direito processual penal. São Paulo, Forense, 1965, v.4, p.389); Anteprojeto do Código de processo penal, do qual resultaram os projetos de lei n.'s $633 / 75$ e 1268/79 (arts. $8^{\circ}$, § único, 235, 256 e 258, deste último).

11. Arts. 9․ § único e 234, do Anteprojeto do Código de processo penal, cuja publicacão foi oficialmente determinada pelo senhor ministro da Justica (portaria ministerial n. 320/81).

12. Declaração de direitos do homem e do cidadão francês. art. 9.; Declaração amaricana dos direitos e deveres do homem. cap. 1, art. 26; Convenção do Conselho da Europa (convenção para a proteção dos direitos do homem e das liberdades fundamentais), art. 6: n: 2; Declaracão universal dos direitos do homem. art. 11, n. 1; Constituição da República Italiana. art. 27: Constituição portuguesa. art. $32, \S$. .

13. Código do processo penal. arts. $11,12,27, \mathrm{e} 46, \S 1^{\circ}$.

14. O procedimento ordinário ou comum compreende seis fases, normalmente: pré-processual ou preparatória, postulatória instrutória ou probatória, decisória, recursal e executória.

15. Tribunal de Justiça de São Paulo. Habeas corpus n: 54.075. Revista dos Tribunais. 268: 83; Tribunal de Alçada do RS Julgados; habeas corpus n: 1769 , v. 10, p.5

16. O mesmo princípio é consagrado no artigo 467 , letra $C$, do Código de processo penal militar. Esta regra já era observada pelo Superior Tribunal Militar como se constata no julgamento do habeas corpus n:27.660. 50: 17

17. Revista de Jurisprudência do Tribunal de Justiça do RGS

18. Supremo Tribunal Federal. Habeas corpus n. 32.208. Revista Forense 150: 393

19. CORRÉA, Plinio de Oliveira. Autoridade competente para ordenar a prisão no direito brasileiro. Ediç̃̃es UFRGS, 1981. 1964

20. ABREU, João Leitão de, A validade da ordem juridica.

21. Lei n: 1.079/50. arts. 16,43 e 76 .

22. Código de processo civil de 1939, art. 159; Código de processo civil de 1973, art. 283

23. Código de processo penal português, art. 345; decreto lei português n: 35.007/45, arts. 12 e 26; Código federal de procedimentos penais do México, art. $1^{\circ}$, inciso II, art. $2^{\circ}$, inciso III: art. 136, inciso IV: art. 137, inciso Il: e art. 168: Código de proce dimentos penais para o Distrito Federal do México, art. $3^{\circ}$, incisos I, II e V, e artigos $5^{\circ}$ e $6^{\circ}$. 